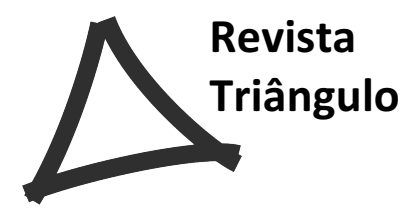

\title{
FORMAÇÃO DOCENTE: A AUTONOMIA NA CONVERSAÇÃO
}

\section{TEACHER EDUCATION: THE AUTONOMY IN A CONVERSATION}

\author{
Marcilena Assis Toledo ${ }^{1}$ \\ Carla Helena Fernandes ${ }^{2}$
}

\begin{abstract}
RESUMO
A escola vem sofrendo grandes mudanças, tendo como maior desafio contribuir na formação de sujeitos conscientes de si e do contexto que habitam. A atuação docente é importante dispositivo nesse processo e a formação continuada pode contribuir significativamente. Referimos-nos à formação que tem como base a reflexão individual e coletiva sobre o exercício docente e os contextos de trabalho. A pesquisa, desenvolvida com professores de uma escola estadual de Pouso Alegre-MG, objetivou, em um espaço coletivo de circulação da palavra, a Conversação, investigar em que medida os dilemas vividos pelos professores quando partilhados com seus pares podem ser mobilizadores de reflexões sobre a prática docente e, como consequência, de formação profissional. Os resultados indicaram que a ausência de autonomia surge como um atravessamento na/da docência, porém a reflexão em espaço coletivo pode contribuir na reapropriação, pelo professor, de seu saber e fazer, o que entendemos como formativo.
\end{abstract}

Palavras-chave: Formação docente. Autonomia. Conversação.

\begin{abstract}
The school has undergone major changes, with the biggest challenge to contribute to the formation of individuals aware of themselves and the environment they inhabit. The teaching practice is an important device in this process and the continued formation can contribute significantly. We refer to formation that is based on individual and collective reflection on the teaching practice and work contexts. The research, developed with teachers from a state school in Pouso Alegre $-M G$, aimed, at a collective space of word circulation, the Conversation, to investigate to what extent the dilemmas faced by teachers when shared with their peers, can be mobilizers reflections on teaching practice and, as a result of professional formation. The results indicated that the absence of autonomy emerges as a crossing to / from teaching, but the reflection in a public space can contribute to the reappropriation by the teacher, of his knowledge and work, what we understand as formative.
\end{abstract}

Keywords: Teacher formation. Autonomy. Conversation.

\section{Introdução}

No contexto de uma sociedade em mudança, à escola tem sido colocado o desafio de contribuir na formação dos novos cidadãos com a construção de educação escolar de

\footnotetext{
${ }^{1}$ Universidade do Vale do Sapucaí - UNIVAS. E-mail: marcilena@gmail.com

${ }^{2}$ Universidade do Vale do Sapucaí - UNIVAS. E-mail: carlahelenafernandes@yahoo.com.br
} 
qualidade que contemple as necessidades sociais reivindicadas pela contemporaneidade, e esse tem sido o mote de discussões promovidas pela comunidade educacional e pela própria sociedade. A atuação do professor, que reflete direta e indiretamente essas solicitações e mudanças necessárias, vem sendo colocada em questão ao se posicionar diante dos alunos, dos pais, dos diretores e da instituição escolar em toda sua dimensão, principalmente, ao se posicionarem diante de si mesmo. Aos docentes se tem solicitado que atendam à demanda que lhes é apresentada de ordem bastante geral, uma vez que está relacionada à economia/mercado, identidade e cultura e, especificamente, à ordem do educacional e pedagógico. Há de se questionar sobre como se percebem os profissionais da educação frente aos desafios postos à sua prática e ainda refletir sobre como, diante da solicitação de inovação e mudança, das necessidades reais de seus alunos e dos apelos sociais, têm lidado no cotidiano escolar com o exercício da docência.

Para HARGREAVES (1994, p. 11) "se quisermos compreender o impacto específico da mudança educativa sobre os professores no mundo pós-moderno, necessitamos compreender igualmente, em termos mais gerais, o lugar que aqueles ocupam no processo de mudança". Segundo NÓVOA (1992, p. 10), o desafio está em potencializar a realidade educacional atual fazendo com que as organizações escolares, no atual contexto das mudanças sociais, venham "configurar novas práticas pedagógicas coletivas abrindo horizontes para um espaço de autonomia profissional dos professores".

A pesquisa que aqui se apresenta, em um recorte, teve como objetivo investigar, em um espaço coletivo criado na escola, em que medida os dilemas vividos pelos docentes e partilhados com seus pares podem ser mobilizadores de reflexões sobre a prática docente e de formação profissional.

\section{Formação Docente e Autonomia - o referencial teórico da pesquisa}

Ao se refletir sobre que formação na atualidade se faz necessária aos professores, NÓVOA (1995, p. 25) diz que a formação está para além da acumulação de cursos, de conhecimentos ou de técnicas, mas se constitui "através de um trabalho de reflexividade crítica sobre as práticas e de (re)construção permanente de uma identidade pessoal". Já em FREIRE (1996, p. 38) encontramos que na formação docente se faz fundamental a reflexão sobre a prática, pois refletindo sobre o que fazem, os professores podem vislumbrar outras 
possibilidades que substituam o saber ingênuo pelo pensar e agir crítico, o que envolve, segundo o autor, o "movimento dinâmico dialético, entre o fazer e o pensar sobre o fazer".

O panorama das mudanças não se dá sem contradições e essa condição se caracteriza, em especial, por "economias flexíveis, globalização, certezas mortas, mosaico fluido, ou sem limites" HARGREAVES (1994, p. 53). Essa expansão e quebra de limites é, como se percebe, contrária ao modelo da racionalidade que ainda hoje vigora nas escolas e redes de ensino, caracterizado por lugares estanques e delimitados, por relações hierárquicas e de mando e por saberes fragmentados e descontextualizados. Na busca pela profissionalização da função docente, a história indica ingerências e desapropriações que impossibilitaram os professores uma atuação autônoma e os dirigiram para o que os autores.

No contexto de mudanças, como fica o professor em relação a sua função? Se a profissão e a formação profissional acontece na relação entre a pessoa, a profissão e as organizações (NÓVOA, 1995), que lugares passam a ocupar (passam a poder ocupar) o professor?

Um paradoxo que se tem observado nesse contexto é a intensificação do trabalho docente, a ampliação da responsabilização dos professores e a constatação de que os papéis profissionais, por se ampliarem, se evidenciam difusos para os docentes. Para este autor, o que de fato acontece é a desqualificação do trabalho do professor a partir de orientações prescritivas e tarefas burocratizantes. Assim, embora o mundo seja de mudanças, o que se coloca para o professor são condições paralisantes em relação ao aperfeiçoamento do seu trabalho tendo em vista este novo mundo.

Ao refletir sobre a atuação docente em tempos de mudanças, frente às solicitações de ampliação das funções profissionais, o que não tem se dado de forma tranquila, se observa atualmente nos professores uma resistência em assumir novas funções. A queixa que fazem é de imposições e autoritarismo que, como no passado, os impedem de construir autonomamente seu trabalho. Para HARGREAVES (1994, p. 133), a teoria da intensificação provoca uma "erosão do trabalho profissional", o que se evidencia na redução do tempo para pensar o trabalho, na redução da qualidade desse trabalho e em uma sobrecarga angustiante, “crônica e persistente". Porém, a escassez de tempo e a ampliação das atribuições não são as únicas causas dos problemas. Frente às mudanças sociais os professores têm sido impelidos a atuar como autômatos. Chamados a atuar em diversos setores escolares, essa atuação não tem sido nem de longe criativa; reproduzem em outros setores e aspectos o que historicamente tem realizado em sala de aula: cumprem ordens. 
A questão da profissionalização e proletarização docente pode ser explicada atraves da categoria/eixo Autonomia (CONTRERAS, 2002). O autor relaciona a autonomia como uma condição profissional e explica a profissão (entre a profissionalização e proletarização) a partir dessa condição. Para ele, na proletarização o trabalho docente sofreu perdas que conduziram os professores, entre outros aspectos, à perda da autonomia. Entre os aspectos e condições que examina, um dos elementos fundantes da proletarização é a lógica racionalizadora das empresas que na educação aconteceu com a inserção da função do especialista e da interferência da administração sobre o trabalho docente. Como já se afirmou modelos curriculares prescritivos, materializados em diretrizes e manuais, reforçavam essa lógica. O professor torna-se um reprodutor e, em consequência, diante do novo, não tem autonomia para agir. Acrescenta-se o aumento das funções, sobretudo de tarefas burocráticas, o que serviu/serve de controle sobre o trabalhador e seu trabalho. Este autor afirma ainda que essa burocratização tem, como consequência, a intensificação de tarefas docentes. Nesse contexto, é preciso refletir acerca de um conceito de gestão que serve a essa lógica racionalizadora. É “o espírito de gestão científica” CONTRERAS (2002, p. 35) que se instalou como modelo da prática educativa e na organização e controle de atuação docente; um processo de produção empresarial/fabril na escola.

A questão da perda da autonomia é, para o autor, um dos mais sérios resultados dessa forma de produção. A dependência externa, as orientações prescritivas, a função de um especialista, retiram do professor a capacidade de pensar e agir autonomamente. Porém, o autor indica algumas saídas e brechas: o Estado ocupa, ao mesmo tempo, a função de fiscalizador/supervisor e de provedor, o que se apresenta aos olhos da população como uma missão. Diante disso, há um apelo social para o desenvolvimento da cidadania e da democratização e para o acolhimento da diversidade. Eis aí uma brecha: há de se encontrar na instituição modos de participação que sejam mais democráticos, situação em que poderá haver relativa autonomia (CONTRERAS, 2002); cabem também ações profissionais coletivas de resistência. Buscar pela autonomia na profissão de professor é um compromisso que vai além da profisssionalidade e se refere à própria educação.

Ao refletir também aqui sobre a formação neste contexto, deve-se considerar os esforços necessários para encontrar soluções diante da complexa questão dos processos formativos, no que está implicada a multidimensionalidade de aspectos que entram na formação do cotidiano escolar. Compreender a escola como lócus privilegiado para a formação continuada (CANÁRIO, 2006), dando o valor devido aos saberes dos professores 
construídos ao longo de sua vida profissional, implica em considerar a formação como processo mobilizado pelo próprio exercício da profissão.

\section{Metodologia}

A pesquisa, de abordagem qualitativa (LUDKE; ANDRÉ,1986; BOGDAN; BIKLEN, 1994), foi desenvolvida com doze professores do Ensino Fundamental e Médio de uma escola da rede estadual de Pouso Alegre - MG e se empregou, como procedimento de investigação, da Conversação (MIRANDA; VASCONCELOS; SANTIAGO, 2006), um dispositivo clínico psicanalítico para trabalho com grupos que se vale de "uma 'associação livre' coletivizada da qual se espera certo efeito de saber" SANTIAGO (2009, p.74).

Com foco na formação continuada, a Conversação abre a possibilidade, no compartilhar com o grupo, de elaboração de novos saberes e/ou de sua (re)significação, formalizando um saber construído a partir de/e em sua prática pedagógica. Para SANTIAGO (2009, p.69), dar ao professor espaço para a palavra possibilita "deslocar-se dos alunos para aquilo que constitui o seu mais íntimo, aquilo que, recusado por ele próprio, se projeta maciçamente para fora dele sobre as crianças e sobre a realidade social”.

A Conversação na escola se deu em um total de dez encontros que aconteceram ao longo do primeiro semestre de 2014; os encontros foram audiogravados e os professores participantes tiveram adesão voluntária ao convite da pesquisadora. Além da Conversação se considera como parte do processo de investigação outros momentos em que a pesquisadora, estando na escola, se voltou à pesquisa de documentos da rede de ensino e escolares (como do Projeto Político Pedagógico), sobretudo buscando dados sobre a formação de professores. O Diário da pesquisadora também foi tomado como instrumento de pesquisa.

O foco dessa escuta da pesquisadora sobre o vivido com os professores na Conversação dirigiu-se pela explicitação dos pontos de conflitos, dificuldades e dilemas que emergiam durante os encontros, e também fora deles, bem como buscou escutar o movimento do grupo através das presenças, das ausências e do silêncio dos participantes. Um dos pontos da análise evidencia a ausência de autonomia do professor, o que se instala como um atravessamento na/da docência com efeitos sobre a atuação do professor. É este tema cuja análise apresentamos neste trabalho. 


\section{Resultados e Discussão}

A análise dos encontros da Conversação, em que participavam os professores e a pesquisadora, fez emergir temas que, como um feixe de fios, constituem as tramas dos saberes da docência. Neste texto apresentamos discussão sobre a temática da autonomia docente.

Para os docentes, o atendimento às orientações da rede de ensino e da escola acarreta sobrecarga de atividades. Queixar-se do excesso de trabalho e do trabalho burocrático (como o preenchimento de formulários, relatórios, tabelas, entre outros) que, segundo eles, não são adequados e producentes ao trabalho docente, foi uma constante nas Conversações. Os professores queixaram-se do pouco tempo para executar tantas atividades estabelecidas e da cobrança de desempenho e produtividade, sem oferecer condições para tal. Estas questões são apresentadas pelos professores como dilemas ${ }^{\mathrm{i}}$ (ZABALAZA, 2004) que têm efeitos negativos sobre sua atuação, no que se inclui o adoecimento. No Diálogo apresentado, os professores afirmaram:

\footnotetext{
"Pesq.: Mas, vamos questionar. Isso que ela traz: 'se a gente fizesse diferente'. Ao fazer alguma coisa diferente, iria trazer alguma diferença? Iria mudar alguma coisa? Prof.1.: Não. Só se a gente recusasse a fazer isso tudo contra esse massacre. Pesq.: Pois é. O fazer diferente que eu estou falando é assim: não é aceitar, né? Ai, quando você se recusa, toma uma posição diferente, né? Você vai causar um efeito diferente! Prof.1.: Ai entra outra coisa. Vão nos dar uma advertência. Pesq.: Advertência? Prof.1.: Eles vão nos dar uma advertência. Pesq.: Ao professor? Ele é advertido por quê? Prof.1.: Por não ter cumprido com... Professores: IDEB, notas, IPEA, avaliação. Pesq.: Quem perde nota? Prof.3.: Nós. Porque você não cumpriu. Eles nos fazem abrir mão. Ano passado mudou tanta coisa. Eu fique em pânico, fui fazer terapia. Minha grande amiga esta aqui, ela fazia terapia comigo. Eu fui pra terapia também. Mas, eu não conseguia, estava preso, não conseguia fazer mais nada. Era tanta cobrança que eles faziam, tanta coisa que eu não estava dando conta. Eu sempre fui muito certinho, sempre gostei de fazer as coisas certas, mas chegou num ponto que eu estava no meu limite. Eu não conseguia pensar, eu não conseguia raciocinar. Eu me sentia só culpa, não conseguia fazer mais nada. [Prof. 1 e 3 em D2C 3$]^{\mathrm{ii}}$
}

Pode-se perceber no sistema escolar uma postura que interfere na possibilidade de ações autônomas dos professores. No Diálogo que se apresenta na sequência, os professores indicam a submissão do seu saber a um outro, externo ao trabalho que desenvolvem.

"Prof.4.: Eu falei que eu ia ficar quietinha, mas não consigo! Pesq.: Que bom, que bom! Prof.4.: Sabe o que é que é? Você tem que ficar assim, você tem que ficar aprovando. Antes 
você entregava a prova paro aluno, né? E você, se o aluno falava cadê a prova? Não, eu te entreguei. Era a sua palavra! Você era um professor, você é um ser que tem palavra. Agora, você tem que passar uma lista que o aluno recebeu a prova. Porque eu tenho que provar pela assinatura na lista que eu entreguei a prova. Agora não existe mais a nossa palavra, tudo tem que ser provado. Então, eu tenho que ter um portfólio do aluno, porque se eu não tiver o portfólio do aluno com... É, ele não pode ser reprovado. Porque eu não tenho uma prova que fiz tudo por ele. Eu tenho que ter documentos provando que eu fiz tudo por ele. Minha palavra não adianta mais. Pesq.: O que é isto? Prof.4.: Ai se você fala, mas eu não tenho tempo para fazer esse portfólio. Então você vai viver outra situação, porque está na lei, que você tem que fazer. Mas não é por ai! Prof.3: Mas nós somos cobrados o tempo todo! Prof.4.: Mas está na lei, então está na lei, se está na lei, você tem que fazer! Prof.7.: A gente tem consciência do nosso trabalho e a gente tem que provar que a gente trabalha! Que a gente produziu, não é? Então isso dai e que é...." [Prof. 3, 4 e7 em D2C3]

A ideia de que a perda da autonomia no trabalho provoca limitações na atuação do professor que se vê insatisfeito, preocupado em responder ao sistema, que também não leva em consideração sua participação no processo educacional. A perda da autonomia está também relacionada à prejuízo na própria identidade profissional, uma vez os docentes se percebem desapropriados de seus saberes (DUBAR, 1997). Também sobre a autonomia, ou a ausência dela, pode ser compreendida por meio dos eixos a autorregulação do trabalho e a obediência às diretrizes externas (CONTRERAS, 2002). Este autor afirma que a autonomia não é uma capacidade, mas uma forma de atuação, uma "qualidade circunstancial" CONTRERAS (2002, p.197), em que a reflexão é indicada como mola mestra.

Quanto maior o interesse e a curiosidade de um profissional pelo saber, melhor ele se posiciona como ferramenta política pela defesa de seus interesses e de seus direitos. Para FREIRE (1997, p.12), essa condição contrapõe-se à postura de "puro seguidores dóceis" de programas construídos dentro de gabinetes, isto é, fora da realidade escolar, que dizem do autoritarismo e da "absoluta descrença" (p.12) na capacidade criadora e na sabedoria dos docentes. Nesse sentido, se adverte que se fala em democracia e em práticas democráticas, mas o que se revela na escola diz de um poder autoritário e centralizador (PARO, 2011).

O que se apresenta na Conversação indica a desapropriação dos professores de suas próprias palavras. Visando superar esse quadro, faz-se necessário a criação de espaços de reflexão propícios para, segundo NÓVOA (1995, p. 25), "uma (re)construção permanente de uma identidade pessoal", que podemos relacionar a um processo de formação profissional.

A oferta de palavra - o que caracteriza e justifica a Conversação ${ }^{i i i}$ (MIRANDA, VASCONCELOS e SANTIAGO, 2006) - tem como objetivo a localização do problema 
identificando aquilo que aparece na escola e para os professores como fracasso, dilema e impasse. O espaço da Conversação (SANTIAGO, 2009) difere de outros espaços escolares no sentido de que neste o professor pode questionar seu próprio papel e atuação, refletindo sobre suas escolhas que, muitas vezes, não correspondem mais ao que dele se espera, ou ao que ele espera de si mesmo. Refletir sobre seus sonhos e escolher qual lugar quer ocupar no mundo é condição para um fazer emancipado e liberto, em cujo seio a reflexão participa (FREIRE, 1996).

O estar em grupo, o expor seus dilemas coletivamente e a partilha de situações que são comuns podem, para o professor, ser mobilizadores de reflexões e de formação. No espaço/tempo da Conversação o pesquisador participa como mediador, mas também os demais professores podem assumir este lugar.

Ao responderem ao questionamento sobre o que foi possível aos participantes da Conversação construírem neste espaço, os professores afirmaram:

"Prof.8. : O que eu entendi, é que a gente está aqui dando um grito. E eu tenho medo que esse grito fique ai dentro desse aparelhinho que você tem virado ai pra mim. (Risos). Eu queria que fosse um grito que todo mundo escutasse. Não adianta eu ir falar com a minha diretora, porque a diretora vai falar com a superintendente, que, por sua vez, vai abrir a constituição ou o Estatuto da Criança e vai falar tudo... Não, não pode! Então, é um berro, de gente que tem muito mais poder nas mãos... Então, que devia ter. Eu me sinto muito, muito pequena. Eu tenho uma missão tão grande na sociedade, e, ao mesmo tempo, eu me sinto tão pequena na sociedade, porque a minha voz é calada, eu não sou ouvida. Prof.3.: Deixa eu falar. Por outro lado, eu achei interessante. Porque a princípio, eu pensei assim, é triste! Você constatar a realidade, o que você realmente está vivendo e falar essa é a nossa realidade. Para mim serviu para isso mesmo. É para encarar mesmo essa realidade, e é isso que eu vou ter que fazer na minha vida, eu vou ter que enfrentar. Isso que eu me dei conta com essas reuniões. $E$ foi positivo num aspecto, que mesmo que nós estejamos aqui compartilhando coisas, na maioria das vezes, negativas, foi importante para a gente sentir que os outros também estão no mesmo barco, não estamos sozinhos. E discordo com a colega, porque historiador, você também é. Quando começaram as transformações, como começaram as mudanças, para o mal ou para o bem, grupos, alguém teve ideia, alguém discutiu, alguém somou com o outro, aquilo cresceu e tomou forma. Talvez, possa ficar devendo, mas a partir do momento que nós percebemos que nós estamos no mesmo caminho, e que nós temos os mesmos problemas, que nós temos que enfrentar juntos, quem sabe isso não vai ser o ponto de partida para nós transformarmos essa nossa realidade e não aceitar o que eles falaram para a gente. Essa é a nossa realidade, mas nós queremos isso ou não? Então, cabe a nós, vamos fazer a nossa parte, independente do poder instituído. Nós sabemos que o povo tem força, que se nos unirmos, nesse aspecto, nós temos força. Não somos só um ou dois. Somos uma classe inteira descontente, os alunos estão descontentes. Eles não podem ignorar as nossas angústias por muito tempo. Isso é o que eu acredito." [Prof. 3 e 8 em D2C6] 
Pensando em práticas de formação que contemplem a complexidade do cotidiano escolar e do exercício da docência, a organização nas escolas de espaços coletivos de interlocução e reflexão pode caracterizar-se como formativo para os professores. No grupo, reunido com os pares, os professores podem, na partilha de situações comuns ou correlacionadas entre o seu trabalho e o de outro professor, refletir sobre essas situações buscando por possibilidades de superação de problemas. A relação entre a reflexão coletiva que se dá no grupo e as inquietações particulares do professor acerca do seu próprio trabalho, uma via de mão dupla, pode caracterizar-se como formativa e influenciar a prática dos docentes em sala de aula.

\section{Considerações Finais}

A partir da ideia de que a autonomia também está relacionada ao pensar, ao posicionar-se em relação a, refletimos sobre a perspectiva de formação que considera que, diuturnamente, o professor encontra-se em autoformação a partir da sua própria atuação. Porém, e tendo em vista a reflexão sobre a prática como formativa, o que dizer da reflexão e de situações dilemáticas (ZABALAZA, 2004), que envolvem frustrações, desrespeito e ausência de autonomia? São essas as aprendizagens? Como promover processo formativo que sustente um profissional pleno de autonomia? São muitos os questionamentos a serem trabalhados.

Através do que foi apresentado pelos professores no espaço da Conversação, podemos afirmar que apesar dos esforços das políticas educacionais, pode-se constatar que os professores, tutelados pelo Estado, são vistos, também internamente, como um corpo incapaz de se autogestar, bem como permanecem sem autonomia e assujeitados às imposições externas. A condição de tutelados dos professores (NÓVOA, 1995) vai da tutela políticoestatal para a científico-curricular, desapropriando os docentes daquilo que deveria lhes ser próprio, seus saberes. A questão da formação insere-se nesse contexto como importante mecanismo de controle, e também de emancipação.

Do que se propôs nesta pesquisa, a circulação da palavra pode contribuir para ampliar possibilidades e convidar a olhar com outros olhos. Um olhar diferente entre tantos outros olhares possíveis, mas que, levando-se em conta a subjetividade e as angústias do professor, venha contribuir em seu processo formativo e autoformativo também. 


\footnotetext{
${ }^{i}$ Para Zabalza (2004), os professores se deparam com situações dilemáticas compreendidas por este autor como "todo o conjunto de situações bipolares ou multipolares que se oferecem ao professor no desenvolvimento de sua atividade profissional" (p. 18).

ii Os Diálogos serão apresentados por D de Diálogo, pelo número correspondente ao excerto retirado de uma mesma Conversação, por $\mathrm{C}$ de Conversação e finalmente pelo número da Conversação. Se indica também quais professores (de 1 a 12) participam deste Diálogo.

iii Conversação, segundo Miller (2005) vem a ser uma situação de associação livre. "A associação livre pode ser coletivizada na medida em que não somos donos dos significantes. Um significante chama outro significante, não sendo tão importante quem o produz em um momento dado. Se confiamos na cadeia de significantes, vários participam do mesmo. Pelo menos é a ficção da conversação: produzir - não uma enunciação coletiva - senão uma associação livre coletiva, da qual esperamos um certo efeito de saber. Quando as coisas me tocam, os significantes de outros me dão ideias, me ajudam e, finalmente, resulta - às vezes — algo novo, um ângulo novo, perspectivas inéditas" (MILLER, 2005, p. 15-16).
}

\section{Referências}

CANÁRIO, R. A escola tem futuro? Das promessas às incertezas. Porto Alegre: Artmed, 2006.

CONTRERAS, J. A autonomia de professores. São Paulo: Cortez, 2002.

DUBAR, C. Formação, trabalho e identidades profissionais. In: CANÁRIO, R. (org.). Formação e situações de trabalho. Porto: Porto Editora. 1997. p. 43-52.

FREIRE, P. Décima carta: mais uma vez a questão da disciplina. In: Professora sim, tia não: cartas para quem ousa ensinar. São Paulo: Olho D’Água, 1997. p. 77-80.

. Pedagogia da autonomia: saberes necessários à prática educativa. São Paulo: Paz e Terra, 1996.

HARGREAVES, A. Os professores em tempos de mudança. O trabalho e a cultura dos professores na idade pós-moderna. Lisboa: McGraw Hill, 1994. 
MILLER, J.-A. et al. La pareja y el amor: conversaciones clinicas con Jacques Alain-Miller en Barcelona. Buenos Aires: Paidós, 2005. p.15-20.

MIRANDA, M. P.; VASCONCELOS, R. N.; SANTIAGO, A. L. B. Pesquisa em psicanálise e educação: a conversação como metodologia de pesquisa. VI Colóquio LEPSI IP/FE-USP. Anais... São Paulo, 2006. Disponível http://www.proceedings.scielo.br/scielo.php?script=sci_arttext\&pid=MSC0000000032006000 100060\&lng=en\&nrm=iso\&tlng=pt . Acesso em: 17 fev.2015.

NÓVOA, A. As organizações escolares em análise. Lisboa: Dom Quixote, 1992.

Formação de professores e profissão docente. In: (org.). Os professores e a sua formação. Lisboa: Dom Quixote. 1995. p.9-33.

PARO, V. H. Crítica da estrutura da escola. São Paulo: Cortez, 2011.

SANTIAGO, A. L. B. Psicanálise aplicada ao campo da educação. Intervenção na desinserção social na escola. In: SANTOS, T. C. (org.). Inovações no ensino e na pesquisa em Psicanálise aplicada. Rio de Janeiro: 7 Letras, 2009. p. 66-82.

ZABALZA. M. A. Diários de aula: um instrumento de pesquisa e desenvolvimento profissional. Porto Alegre: Artmed, 2004.

RECEBIDO EM: 02/03/2016

APROVADO PARA PUBLICAÇÃO EM: 29/06/2016 